\title{
Application of terrain analysis to the mapping and spatial pattern analysis of subsurface geological fractures of Kuala Lumpur limestone bedrock, Malaysia.
}

\begin{abstract}
Subsurface geological fractures in karst terrain are often associated with unpredictable environmental and geotechnical engineering problems. This requires precise mapping and an understanding of the distribution of geological fractures on multi-scales. To extract and investigate surface and subsurface geological fractures on such scales, multi-scales, this study presents two approaches. The first involves geological prediction and visual interpretation of terrain parameters using a digital elevation model (DEM). The second is an automatic detection method using a topographical fabric algorithm that uses a DEM to create a map of ridges, which represent the footwalls of geological fractures, and valleys (channels), which reflect geological fracture zones. Unlike wavelet analysis and the Fourier transform, which use optical remote-sensing images, the integration of visual interpretation and a topographical fabric algorithm is capable of the extraction and spatial correlation of subsurface geological fractures. This method was applied to Kuala Lumpur limestone bedrock in Malaysia, by focusing on the adjacent mountainous areas and the geometries of ex-opencast mining ponds. The spatial correlation of the extracted surface geological fractures was clarified by rose diagrams and semivariogram models. Spatial correlation shows that the Malaysian peninsula, surface and subsurface geological fractures and the geometry of ex-opencast mining ponds share similar trends. The results obtained using this methodology is compared to those of subsurface geological fractures reported by means of geophysical surveying and field investigation. This proposed method may be useful for mapping geological fractures in areas of high soil moisture, where geophysical surveying is difficult and/or not available, and is also highly applicable in other parts of Malaysia or Southeast Asia, permitting a better understanding of the geotectonics and geotechnical engineering setting of the study area.
\end{abstract}

Keyword: Remote sensing 